\section{"Employability is not inimical to good learning" *: rearticulating school academic curricula to surface their employability value}

Employability value of school curricula

\author{
Kate Daubney \\ The Careers Group, University of London, London, UK
}

\begin{abstract}
Purpose - This paper introduces a new approach to extracting the employability value of school/further education (FE) curriculums, using textual analysis to surface the transferable skills from UK curriculum documentation. The higher education extracted employability concept already established by the author is applied to help learners articulate the skills value of their knowledge-focused qualifications, closing the gap between the academic learning and the workplace. Proposals for additions to existing curriculum documentation would enable delivery of the Organisation for Economic Co-operation and Development's (OECD's) aspiration to embed skill development in school education.

Design/methodology/approach - Manual textual analysis of United Kingdom A Level, General Certificate of Secondary Education (GCSE) and Scottish academic qualifications surfaced a database of transferable skills, which are categorised, and their interrelationships were analysed.

Findings - Relatively few skills are explicitly articulated in curriculum documentation, revealing issues for learners recognising and articulating transferable skills. Extracted employability surfaces significant value from curriculum by identifying over 200 transferable skills, framed in the language employers recognise, thus closing the perceived "skills gap". Comparisons reveal significantly greater diversity of skills innate to subjects perceived as "less academic".

Practical implications - Learners will find it easier to recognise a comprehensive language of transferable skills, aligned with what employers need, and fundamental to career decision-making through understanding the relationships between academic qualifications and work.

Social implications - Learners who understand the wider value of their qualifications beyond knowledge focus, particularly in relation to transferable skills, are better able to be join, navigate and be agile in a challenging employment market.
\end{abstract}

Originality/value - Higher education (HE) concepts of employability are not well-established or understood in schools. This new approach articulates it through transferable skills within existing academic curriculum.

Keywords Skills, Education policy, Employability, Curriculum, Schools

Paper type Research paper

\section{Employability? Huh?}

Ask any pre-18 learner if they know what "employability" means, and they might reply with a clueless shrug of the shoulders. They might hazard a guess, but it might also be the first time they have even heard the word. Yet when they enter university or the workplace, they will suddenly find it not only pops up everywhere, but with the expectation that they understand its meaning too.

One of the issues with "employability" is that there are a number of definitions in circulation, most of which have been created for scholarly purposes rather than educational

C Kate Daubney. Published in Journal of Work-Applied Management. Published by Emerald Publishing Limited. This article is published under the Creative Commons Attribution (CC BY 4.0) licence. Anyone may reproduce, distribute, translate and create derivative works of this article (for both commercial and non-commercial purposes), subject to full attribution to the original publication and authors. The full terms of this licence may be seen at http://creativecommons.org/licences/by/4.0/legalcode

* Knight and Yorke (2003). Employability and Good Learning in Higher Education. Teaching in Higher Education 8 (1): p. 3.
Received 28 August 2020 Revised 12 October 2020 Accepted 18 October 2020 
JWAM

13,1

104 ones, and certainly not from the learner's point of view. The broad adoption of Yorke's definition (2004, p. 7) by many universities has established it prominently: "a set of achievements - skills, understandings and personal attributes - that make graduates more likely to gain employment and be successful in their chosen occupations, which benefits themselves, the workforce, the community and the economy". Hillage and Pollard (1998) separate out career management planning and job application skills from workplace requirements, as well as identifying what is shaped by social capital: the combination of family responsibilities and external factors that impact whether someone can make the most of the assets they bring and the opportunities available to them (p. 3). Harvey's paper for the Higher Education Academy (2003) identifies that "Employability is not a "product" but a process of learning" (p. 2), which situates it in the educator's responsibility to enable, by ensuring reflective activity can take place. And employers themselves have a view: sector bodies including the Confederation of British Industry and the Institute of Student Employers regularly publish findings from member research, articulating required elements including commercial awareness, a "can do" attitude and an entrepreneurial mindset in conjunction with a broad set of transferable skills (e.g. CBI, 2019; ISE, 2020).

But the challenge in making this meaningful for pre-18 learners is considerable. Even the formal Statutory Guidance issued by the United Kingdom (UK) government for careers provision in schools and colleges (Department for Education, 2018) only superficially engages with employability: it mentions it twice, but clearly with the assumption that any teacher or careers professional applying the Guidance will know exactly what it means. Of the eight Benchmarks in the Guidance against which provision is evaluated [1], four relate to some aspect of the workplace, but none of them explicitly outlines how learning about the workplace should be applied to enable learners to understand or develop their employability. One of those, Benchmark 4 "Linking curriculum learning to careers", hints at the connection that is surfaced by the more academic definitions summarised earlier, but it focuses on a very linear interpretation of the relationship between subject and career outcome, as if this might solve the conundrum of what employability is: "All teachers should link curriculum learning with careers. STEM subject teachers should highlight the relevance of STEM subjects for a wide range of future career paths" (p. 7). In other words, the emphasis is on the ability to be employed in these sectors. This only creates more problems for educators: what about those subjects which do not have an obviously linear relationship between knowledge and a career choice? And what is it in the curriculum that they should be linking to or emphasising?

The answers matter for three reasons. First, as I will outline further below, employers perceive there to be a gap between the skills of the learners they recruit at 18 and at 21 and the skills they need; this needs to be explored before it can be addressed. Even if in the UK, these numbers recruited at ages 16-18 are significantly smaller than those entering further and higher education (Department for Education, 2019), it is still fundamentally important that these learners are supported effectively into work, and it would be incorrect to assume that those remaining in higher education (HE) are supported significantly more effectively in this respect (see Daubney (2020) for a discussion of this issue in the HE context). Second, in a coronavirus (COVID) world that makes entry to work more challenging than ever, learners will need to be flexible, agile and very confident about how their education enables them to enter work successfully. The Organisation for Economic Co-operation and Development (OECD) has repeatedly identified the importance of lifelong skill development in order for countries to "adapt and thrive in a rapidly changing world" (2019, p. 41), and it specifically recognises that "improving the credibility of skills assessment and recognition systems requires designing tools that are relevant to employer needs, relevant to learners' needs, [and] embedded in national qualifications frameworks where possible" (2019, pp. 112-113). But UK curriculum currently offers very little for teachers to support that goal, and there is no infrastructure in UK pre-18 education reflecting the OECD's aspiration for skills reform. 
Third, notwithstanding policy perspectives and perhaps most importantly of all, as a learner living through a pandemic, it is very difficult to make a confident decision about even a first career step when you do not know what you offer, or how your qualifications might prepare you for whatever is coming next.

At workshops and conferences where I have trained and worked with educators of all subjects on this topic, overworked teachers often tell me-as their HE counterparts do-that they feel that teaching employability is not their job. It feels like something extra to do, something that does not belong in the academic programme, something they do not understand and cannot control, something imposed from outside. Yet despite the inadequacies in the Statutory Guidance and much of the supporting documentation, employability is actually already there in curriculum, and teachers are already teaching it.
Employability value of school curricula

\section{Qualifications as knowledge assets}

A fundamental issue in identifying the relationship between employability and pre-18 curriculum is that qualifications have been entirely constructed as assets of knowledge. One does not have to dig down far into the curriculum documentation supporting teaching at school, further and even HE levels to appreciate how significantly the focus rests on the acquisition of knowledge as the definition of successful study and learning. Even the UK Department for Education Teachers' Standards Overview lists "Good Subject and Curriculum Knowledge" (2011) above the skills of teaching. For schools in England, the curriculum is outlined through the National Curriculum (2014) and several of the introductory documents focus on what is to be learned and understood. Science programmes of study (2015b) are introduced as "understanding the world through the specific disciplines of biology, chemistry and physics....all pupils should be taught essential aspects of the knowledge, methods, processes and uses of science." Likewise, "[a] high quality history education will help pupils gain a coherent knowledge and understanding of Britain's past and that of the wider world" (2013).

At further education (FE) level, A and AS Level qualifications are similarly aligned. The Subject Content for A and AS Level Geography "should encourage students to gain enjoyment, satisfaction and a sense of achievement as they develop their knowledge and understanding of the subject" (2014c, p. 3), and Computer Science identifies first the requirement for students to develop "an understanding of, and the ability to apply, the fundamental principles and concepts of Computer Science, including abstraction, decomposition, logic, algorithms and data representation” (2014a, p. 1).

The extension of knowledge into associated specialist skills also commonly occurs. The key stage 4 Mathematics curriculum leading to the General Certificate of Secondary Education (GCSE) examination instructs that "[a] high-quality Mathematics education...provides a foundation for understanding the world, the ability to reason mathematically, an appreciation of the beauty and power of Mathematics, and a sense of enjoyment and curiosity about the subject" (2014e, p. 3). Philosophy at A and AS Level engages students to "develop an understanding of the core concepts of philosophy and begin to develop their own skill of conceptual analysis, through the study of the ways in which philosophers have analysed concepts and have, through conceptual analysis, identified subtle differences which have a wider impact on philosophical arguments" (2015a, p. 3).

Hudson et al. (2015) identify a key problem arising from this focus (with reference to teaching in Scotland) which they describe using Schneuwly's term of "didactic transposition": "the knowledge in question is not knowledge for acting and solving problems in the social contexts in which it was created and where it is used, but it is instead transposed into knowledge to be taught and to be learned. ...[T] here is a "rupture" between daily life and school, which changes the knowledge profoundly" (p. 377). That presents a significant 
JWAM

13,1 problem when "linking curriculum learning to careers" and also to making any sense of how employability is developed in learners before they enter the workplace for the first time. But if we focus on the one element of curriculum-skills-which is fundamental to the connection between school and daily life, by definition in itself "transferable", then this rupture need not occur. And if, by extension, we not only thought of knowledge as important, but de-relegated the skills and attributes which make the acquisition of knowledge possible, then we have bridged the gap and positively reinforced the connection.

It is easy to see how the dominance of acquisition of knowledge has created increasing problems for the relationship between education and the transition to work, the higher the level of education studied. The Institute of Student Employers (ISE), which represents those recruiting university graduates, reported in 2019 that only $15 \%$ of their members were looking for a specific degree subject (p. 51), down from 19\% in 2017 and $23 \%$ in 2014, which seems to reinforce Thijssen et al.'s proposal that "the 'half life' of [higher education] qualifications is becoming shorter" (2008, p. 166). But those same employers also identify significant gaps in what non-graduates bring. In early 2020, the vast majority of employers were confident they could recruit non-graduate entrants with skills like teamwork, numeracy and IT skills, but the gap widens quickly in other skill areas. $20 \%$ said their non-graduate recruits were lacking problem-solving skills, $48 \%$ said non-graduates lacked negotiating and influencing skills, and $54 \%$ said their recruits were lacking skills in dealing with conflict (ISE, 2020, p. 18). These are skills that are readily developed across any subject that involves discussing and sharing ideas, but learners are apparently not able to recognise or articulate that. Key to this is the ISE's additional finding that $41 \%$ of employers said that non-graduates lacked self-awareness (p. 18): they do not know that their academic experience is developing their transferable skills. It is these transferable skills which will underpin learners' ability to pick up the specialist sector-related skills that are more commonly reported in skills' gap analyses (e.g. Campbell, 2016, p. 13)

So exactly how does the improvement of knowledge connect to the improvement of workreadiness, if so many graduate employers are not looking for a specific degree subject? And what does this mean for young people entering the workplace at 18 instead of going to a university? How can they understand better how a school and college education actually prepares them to be successful in the workplace?

\section{To get there, I would not start from here}

Considering a non-STEM subject like History, it is easy to see the problems created by Statutory Guidance Benchmark 4. Across the curriculum documentation for GCSEs, A Levels and Scottish Nationals, Highers and Advanced Highers, those for history make it very difficult to find the evidence of how a teacher would link curriculum learning to anything relating to a career journey or a learner's ability to be successful on that journey. Careers professional witness how learners are often paralysed in career discussions by the apparently few career choices that follow directly from History: historian, archivist, heritage professional.

But if we step up a level to HE, the curriculum documentation is a little more helpful. In 2017, I developed a new and original approach to surfacing or "extracting" the employability value of HE qualifications for a UK Russell Group university by doing a detailed manual textual analysis of all 61 of the Quality Assurance Agency's Subject Benchmark Statements for bachelor's degrees (Daubney, 2020). These documents provide the backbone for all HE curriculums in the UK, but they are also written with employers in mind. Indeed, all Statements suggest that among those to find value in the Statements would be "an employer, to find out about the knowledge and skills generally expected of a graduate in [this subject]" (e.g. Dietetics, 2017, p. 1). 
My analysis involved identifying both explicitly and implicitly expressed transferable skills and attributes, in other words those required and developed across a wide range of subjects and employment roles, while not being anchored to any of them. For example, a paragraph like this from English (2015, p. 6) embeds transferable skill groupings (e.g. applying methodologies, evaluating, exploring perspectives etc.) into the specialist context:

Descriptive, critical and theoretical approaches to language are explored alongside key subdisciplinary areas such as pragmatics, discourse analysis, language history, dialectology [etc.].

But unpacking this language is not necessarily comfortable territory for academics. Understanding their concerns that employability is not academically rigorous and recognising their feeling that writing employability-led learning outcomes was neither their responsibility nor appropriate for a research-led curriculum, I wanted to demonstrate exactly why it is that employers recruit graduates. Because employers do just that, even if my experience of being a HE careers professional indicates that students are not always very good at articulating what they offer. And those same employers increasingly recruit learners straight out of school and college, because these learners too have something to offer: even if they have minimal work experience, pre-18 learners enter the workplace with some relevant work-related capacity. So what is that capacity, and how could we do a better job of identifying that for learners and helping them gain the benefit of it?

My HE textual analysis surfaced over 200 different transferable skills from the Subject Benchmark Statements, skills that were common to multiple different subject areas across many different disciplines. It also surfaced over 50 "attributes" (defined here as qualities, behaviours and values) which I expanded to a list of 80 by cross-referencing to attributes prioritised by the type of employer bodies identified above but still consonant with curriculum content. It also surfaced the value of "experience": the way in which curriculum learning enables learners to put those skills and attributes, as well as their subject knowledge, into practice. This approach, which I call Extracted Employability and capture through the KASE Framework, has created significant traction for HE academics and careers professionals seeking to help students and graduates articulate more effectively the value they gain from their curriculum learning. The 200 transferable skills alone offer a far richer language for writing learning outcomes, and for students to write CVs and applications that indicate just how their subject study enables them to be well suited for careers that are not connected linearly to their programme. These skills are not forced or parachuted in through extra- or co-curricular content or learning outcomes which do not belong. They are the skills that already exist in the academically rigorous curriculum and are innate to the subject. And these are the same transferable skills that employers are looking for, articulated in the more granular way that employers are seeking. So if we consider subjects like History or Philosophy, whose graduates are sought after in the financial services and management consultancy sectors, we can see that students can both love their subject and find long-term career opportunities based on its wider value beyond only specialist knowledge of global wars or existentialism.

While the qualifications, teaching and learning experience are different pre-18, the same problem exists, as does the same potential in curriculum. So what happens if you make it easier for learners to identify the transferable skills they develop through their subject study, the same skills that employers want to develop in them? I applied my existing textual analysis approach to the A Level curriculums of 36 subjects, as published by the UK Government, cross-referencing to Scottish qualifications and GCSEs, to extract only the transferable skills. It is a much more challenging analysis of school curriculum documentation, because the focus on knowledge gain is far more dominant, and the process of extracting the underlying transferable skill innate to that type of knowledge gain requires pedagogical expertise as well as disciplinary insight. It is also important to emphasise that this is not a matter of skills
Employability value of school curricula 
JWAM

13,1

108 developed through the teaching delivery or learning style: collaborative versus didactic, for example. These are the skills that are innate to the subject.

\section{History: past, present, future}

For example, here are four of the skills I surfaced from my first phase analysis of the A Level History curriculum (Department for Education, 2014d).

(1) Analyse and evaluate the significance of [individuals, groups, events, developments and ideas]

(2) Comprehend, analyse and evaluate how [the past] has been interpreted in different ways

(3) Demonstrate their breadth of knowledge and understanding by making links and drawing comparisons between different aspects of [the period, society or theme studied]

(4) Analyse and evaluate the causes and consequences of [historical events and situations]

With the italicised text in place, it is clear that these are skills innate to History. But if we substitute the expression "the data" for the words in italics, we can immediately recognise these same skills in Accounting, Physics or other sciences. If we substitute "the use of this technique" in the first three bullet points, we could apply this skill in Art or Music or other creative subjects. If we substituted "applying this theory" into the last bullet point, we could be learning Sociology or Geography or Psychology. And if we are looking at a career in accountancy, we can see that these neutralised skills are exactly those required for digging through financial information, evaluating its importance, constructing an explanation or narrative and determining its impact.

But we do not teach curriculum in this way. And by not doing so, we not only make it very difficult for learners to understand and recognise the value of their learning as it happens, but also to make connections between different subjects or to connect their academic learning to future roles and careers.

During phase 1 of my analysis, it became clear that the pre-18 curriculum documentation referred explicitly to far fewer skills than I expected or was hoping for, particularly in comparison with their HE counterpart documents. So, in phase 2 of my analysis, I looked for skills which are more deeply hidden and not articulated as clearly as the four above, yet which surely are required to be developed in order to meet the curriculum requirements. For example, there are two references to "research" in the History A Level curriculum:

(1) Develop the ability to ask relevant and significant questions about the past and to research them

(2) Carry out a historical enquiry that is independently researched and that investigates specific historical questions, problems or issues; this should utilise, as appropriate, the knowledge, skills and understanding outlined above

But nowhere in the curriculum (or that of other subjects) does it outline what research skills are. So, I identified skills which are fundamental to "research" and surface in other subjects, including:

(1) Explore relevant resources (Geography)

(2) Gather relevant information or evidence (Archaeology)

(3) Organise information and research findings appropriately (Art and Design)

(4) Define research questions (Geography) 
Those skills are not directly expressed in the History curriculum, but it is reasonable to assume from a pedagogical and skill development perspective that when "research" is mentioned, these are among the constituent skills required, as well as being skills that exist in their own right.

Again, the curriculum documentation makes it very hard for learners and for teachers to surface enough of the skills required to meet these learning objectives, because there is so little articulation of the range of skills that underpin them. But if that range of skills were to be articulated more fully in the curriculum documentation, the source reference point for all syllabuses, it would make it far easier for teachers and learners to articulate the learning journey in parameters other than knowledge, that enable the learner to recognise and refer to the longer term value of their qualifications.

\section{The wood and the trees}

My analysis of pre-18 curriculum was focused on skills and, similarly to my analysis of $\mathrm{HE}$ curriculum, I surfaced over 200 transferable skills over the two phases mentioned above. In the curriculum documentation, as the "research" example indicates, many of these skills are presented in an implied form: it is expected that somehow the student will have be aware of and have accumulated the necessary underpinning skills. For example, the fourth History example above expects learners to "analyse and evaluate the causes and consequences". How is a learner to evaluate? How do they understand what it means to analyse and evaluate? When and how do they learn what the component skills are of evaluation, and how to recognise which ones to deploy?

But there are also composite skill descriptors in the curriculum documentation, where a huge number of undifferentiated skills are combined into one. Two of the main culprits are "analyse" and "communicate". From Dance to Accounting, Film Studies to Science, communication skills are articulated as required for effective demonstration of the subject. In my analysis, I have created two main categories of communication skills: written/verbal/ visual and interpersonal. Examples of these respectively include:

(1) Present data appropriately

(2) Summarise extensive information concisely

(3) Draft and edit content

and

(1) Facilitate, evaluate and incorporate others' contributions

(2) Give constructive feedback

(3) Understand how audience influences interpretation

My analysis surfaces 28 different skills across these categories, compared to a total of more than 60 individual communication skills across four categories in my $\mathrm{HE}$ analysis, which more closely resembles the nuance and differentiation employers are looking for both in graduate application processes and in graduate roles. But even at pre-18 level, as the ISE Development Survey (2020) referenced above indicates, in order to enter and meet the requirements of the workplace learners are going to need to know what these communication skills are at a far more granular level than the curriculum documentation presents them. So again it would realise huge benefits to learners if teachers were able to use curriculum to articulate and consistently refer to these skills each time they surface.
Employability value of school curricula 
JWAM

13,1

110

However, those 200 skills are challenging to navigate, particularly for any learner who is unfamiliar with them in abstract, let alone in the context of their subject study. And from my experience navigating experienced academics and teachers through this analysis, let alone watching them coming to terms with a significant and new employability subtext to their otherwise familiar curriculum, I know that too much information is as unhelpful as too little. Categorising the skills is a key way into this new approach, so my analysis surfaces the following structural grouping to the skills (see Figure 1 below):

A striking observation from the grouping in Figure 1 is just how many categories and individual skills surface under "analyse": around $70 \%$. This is comparable to my HE analysis and, referring to Bloom's Taxonomy of Educational Objectives, these are the skills required to underpin all the stages of the application of understanding. However, a key question arises about the detail in which we should introduce learners to these individual skills, and at what stages in their learning. Notwithstanding the obvious risk of overwhelming the learner with all this new language for their learning experience, there is value in exploring potential applications of DeKeyser's Skill Acquisition Theory (2015), albeit not in the confines of this article. My analysis makes the case for the importance of what DeKeyser calls "declarative knowledge" of these skills at a very early stage (e.g. There is a skill called "making connections"), in order that the stage of "procedural knowledge" can follow soon after (e.g. This is what it means to "make connections" and this is how "make connections" is applied alongside skills of "evaluate the significance of key factors" and "sift arguments") (2015, p. 95). Unlike learning algebra before learning calculus, I propose that the sooner the learners can recognise the range and detail of transferable skills they are using, the better, rather than introducing them in a hierarchical way. For a learner easily put off by seeing only difficulty in algebra and not beauty, recognising that they are solving problems and learning to look at the

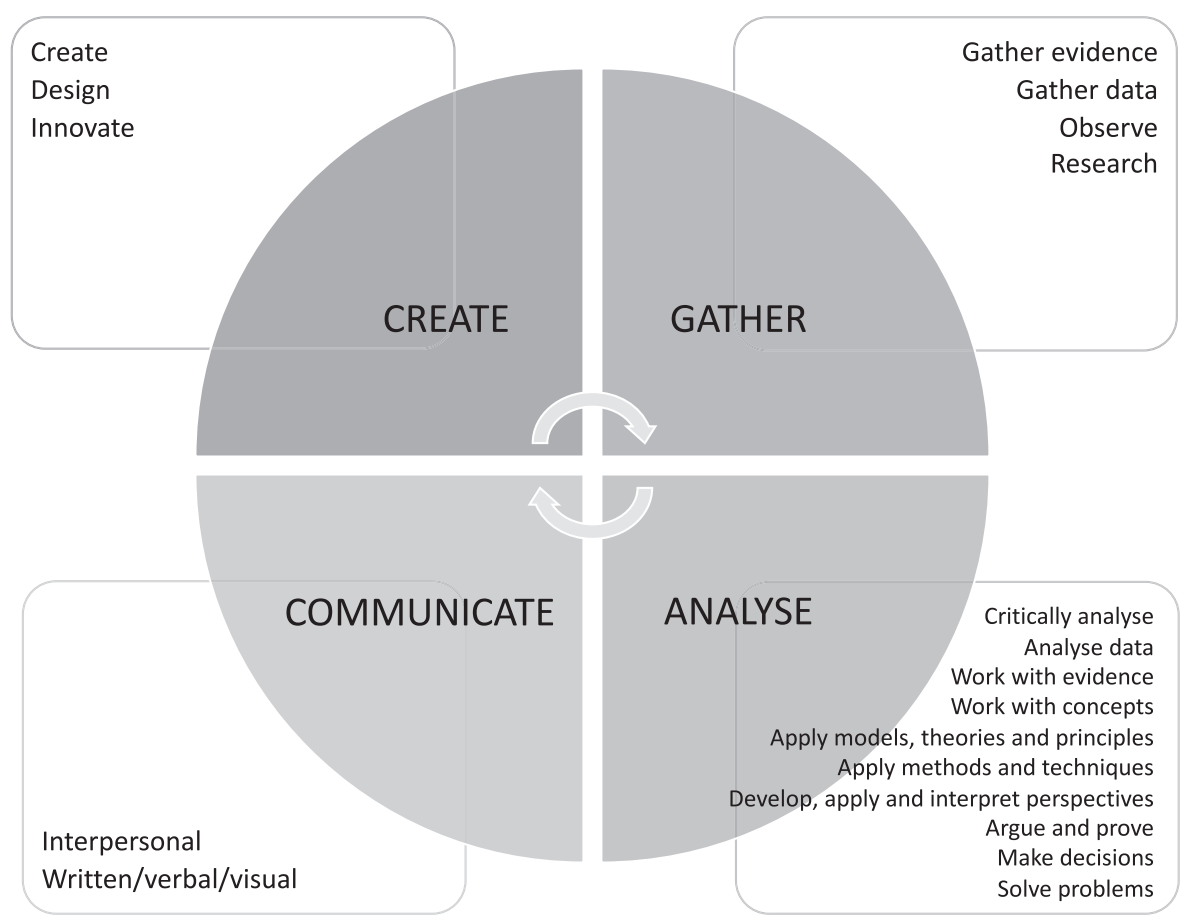

Figure 1.

Pre-18 Curriculum Transferable Skills Analysis: top level categories (C) Daubney (2020) 
same situation from different angles provides an incentive to stay the course. DeKeyser's final stage, the "Automatization of knowledge" of those skills (p. 96), is the aspiration for successful learners in the workplace, but I would propose that "procedural knowledge" is the critical stage for learners to make an effective preparation and transition into work. This is because the level of self-awareness is not only desired by employers, but also what they need to make connections between study and their choice of career or first workplace role.

\section{Building connections, revealing selves}

Using this structure, it is therefore not only possible to introduce learners to the types of skills they will be developing, but also to reveal relationships between subjects that are otherwise not visible to learners. One of the key challenges that learners face in school and FE is identifying combinations of subjects to study towards qualifications at 16 and 18 . Even the best careers guidance professionals can find it very difficult to help learners evaluate and harness the benefit of the combinations of subjects they love, both against a backdrop of perceived "good combinations" (Maths, Physics, Chemistry) and against the perception that some subjects are less academically credible than others (for example Sociology, Design and Technology, Dance). My skills analysis however reveals information about the relationships between subjects at a skills level that makes it easier to understand why some learners seek similarity while others seek complementarity, and also debunks the myth that some subjects are less useful to learners in the longer term.

The foundational relationship between Maths and both science subjects and subjects like Accounting and Economics is clear, but the synergies of transferable skills make that much more obvious. For example, drawing on the structure in Figure 1, learners of all these subjects are developing the skills of applying models, theories and principles. For a learner who is asked by a teacher or an employer "Why do you like these subjects?", an answer that can draw on better evidence of synergy, such as "I like extracting information to help me solve a problem" or "I like to evaluate my experiments" or "I like to see how all these different ideas are connected by one unifying idea", will be far more useful to the learner in any context where the subject knowledge no longer applies, because it will also be exactly what an employer will want them to do in a role. So a learner going from Chemistry GCSE into a career in food will progress more quickly if they recognise that evaluating why one cake batter rose better than another is a fundamental skill they already know, use, and can continuously reapply.

But if we then look at all the other subjects that include skills from the category of applying models, theories and principles, there are some surprises: Business, Law and Politics may not seem so unlikely, but Dance, Religious Studies and History of Art might well seem odd bedfellows to the sciences, particularly from the learner's perspective. From a career exploration point of view, however, this synergy and similarity is fundamentally valuable. Using these connections to enable learners to navigate their own choices, values, interests and passions through frameworks that are tangible and meaningful in the landscape of work is vital. Because a learner who is confident to say why they like both Dance and Physics, and how they see the connections and complementarity, is a learner who will be able to see connections and complementarity in work too. As above, employers constantly emphasise the importance of self-awareness as a key attribute in successful employees, and it is also a key element in career exploration (e.g. the models of Holland or Super; see Yates, 2013).

Another important revelation from my analysis of pre-18 curriculum is how many transferable skills are developed through subjects that are often considered "less academic": not just some of the creative subjects like Dance or Drama, but Physical Education, Sociology, Music Technology or Design and Technology. These are subjects which not only develop a relatively higher number of transferable skills alongside highly specialised knowledge than conventional subjects, but also across a wider range of categories of transferable skills. When
Employability value of school curricula 
JWAM

13,1

112 compared with traditional humanities subjects, these more recent additions to curriculum demand and develop far greater skill diversity and agility in the learner. That again is a key factor in preparing them for the demands and opportunities of work, and is a property of those subjects that is, in my experience of working with teachers and learners, vastly misunderstood and undervalued by policymakers, parents, the media and, to some extent, employers. Table 1 (below) shows a comparison between the categories where I surfaced skills from the English Literature curriculum and that from Physical Education.

\section{Mind the gap}

However, none of these values can be realised by the learner without infrastructures in curriculum to make that learning clear and obvious and to enable them to recognise and articulate it. Whatever the degree of granularity with which skills are labelled, the value to teachers of existing curriculum documentation would be significantly enhanced if all documents included consistent statements about which transferable skills are innate to the subject, and if learners had access to holistic models such as the one I have developed from my analysis that reveal relationships between skills surfacing in different subjects. Learners perceive that History of Art and Maths are as different as careers in tax audit and journalism, but to see common skills such as "forensic attention to detail", "reformulate arguments" or "question effectively" across both subjects and both careers adds significant scaffolding to a learner's journey of career exploration and to their confidence to take that journey. At a time when educational experiences are challenging and the labour market is under exceptional pressure, learners need all the help they can get to maximise the benefit and value of their education in the longer term. But they need the language to articulate that value, and a decision by education policymakers to make a simple enhancement to all curriculum documentation would immediately give them that language.

For example, the Ancient Languages A Level curriculum (2017) includes the requirement that learners must "demonstrate their ability to recognise, analyse, explain and/or deploy syntax and accidence" (p. 5). This could be enhanced significantly by standardised wording common to all curriculums including the skill "to explain", and shared with learners, which I propose could read along the lines of:

\begin{tabular}{lcc}
\hline Category of skill (see Figure 1) & English Literature & Physical Education \\
\hline Create & $\mathrm{X}$ & $\mathrm{X}$ \\
Design & & $\mathrm{X}$ \\
Innovate & & \\
Gather evidence & & $\mathrm{X}$ \\
Gather data & & $\mathrm{X}$ \\
Observe & $\mathrm{X}$ & $\mathrm{X}$ \\
Research & & $\mathrm{X}$ \\
Critically analyse & $\mathrm{X}$ & $\mathrm{X}$ \\
Analyse data & & $\mathrm{X}$ \\
Work with evidence & $\mathrm{X}$ & $\mathrm{X}$ \\
Work with concepts & & $\mathrm{X}$ \\
Apply models, theories and principles & & $\mathrm{X}$ \\
Apply methods and techniques & & $\mathrm{X}$ \\
Develop, apply and interpret perspectives & $\mathrm{X}$ & $\mathrm{X}$ \\
Argue and prove & $\mathrm{X}$ & $\mathrm{X}$ \\
Solve problems & & \\
Make decisions & & \\
Interpersonal & & \\
Written/verbal/visual & & \\
& &
\end{tabular}

Table 1. Comparative analysis of skills categories surfaced in English Literature and Physical Education A level curriculums (C) Daubney (2020) 
You will explain orally and in writing. Explanation includes the skills of constructing and presenting arguments, articulating definitions, critiquing the arguments of others, influencing and persuading, understanding how audience influences interpretation, expressing ideas with nuance, summarising information effectively, and making accurate reference to sources. You will also draw on the skills of effective listening and questioning when explaining orally, and drafting and editing content when explaining in writing.

Giving learners clearer language also addresses another key problem: the perceived skills gap. There is no doubt that there are skills shortages in some key specialist areas, and the UK government's emphasis on STEM in Benchmark 4 of the Statutory Guidance on careers discussed above indicates where some of those shortages lie. But against the backdrop of competing narratives of STEM, of the importance of humanities study, the decline of Music and creative subjects in schools, and the loss of language teaching at all levels of education, a holistic approach to articulating skills across all disciplines would reinforce the value of all academic learning beyond the qualifications gained. It would also enable learners to show that they do have many of the transferable skills perceived not to be present.

\section{Conclusion: employability - yes!}

I propose, therefore, that just two core additions to curriculum are required to realise this innate employability value when taught:

(1) A framework of transferable skills that defines them clearly and consistently across all curriculums, so that teachers and learners understand and recognise common skills when surfaced from different subject contexts

(2) An infrastructure of the relationships between transferable skills that defines how they connect and complement across different subjects

These are not complex additions, but they are transformational. They require a simple but consistent rewriting of curriculum documentation. But for educators in the classroom they provide additional reference points or touchstones that tie lessons, activities and learning together for learner benefit. Because the benefit to learners-and therefore to employers-must be our motivation.

While COVID has created an unprecedented crisis for learners entering work, the issues addressed by surfacing the transferable skills from academic curriculum originate far further back in the disconnected relationship between much of education and work. Creating new qualifications such as $t$ Levels does not solve this disconnection: $t$ Levels, like BTECs, still focus on the specialist skills and knowledge for one industry, not the transferable skills and attributes that enable learners to move into and across many industries, particularly in uncertain times. So everyone benefits from a better understanding of how traditional qualifications develop future capacity to learn the specialist knowledge and skills of every role. But given a pre-18 academic curriculum so focused on specialist knowledge gain to differentiate subjects, a complementary focus in the same curriculum on the transferable skills that connect subjects would fundamentally enable learners to understand and recognise that no matter their mastery or love/hate of subject, they are gaining other value that will stay with them long after they have forgotten titration or the ablative case or the first line of Romeo and Juliet.

Curriculum is not currently designed to do this, but if we are to prepare our learners for an incredibly uncertain employment market, we must fundamentally change the way we talk about learning to under-18s in the UK. There is an urgent need to revisit and renew the value of mainstream academic curriculum to ensure that it remains relevant to learners at all ages. A learner who understands that titration is about solving a problem, the ablative a way to
Employability value of school curricula 
JWAM

13,1

\section{4}

understand how language is built, or Romeo and Juliet a case study in resolving conflict will find engagement in one subject enables enlightenment in another, and they will recognise their academic past in their working future. And for teachers who want to ensure that learners get the maximum benefit and value from every moment in the classroom, extracting employability from the school curriculum does not obstruct it. Instead, it preserves its value in the longer term.

\section{Note}

1. The Benchmarks in the Statutory Guidance were first developed by the Gatsby Foundation in 2014, and then adopted in their original form by the UK Government in development of the Statutory Guidance.

\section{References}

Campbell, M. (2016), The UK's Skills Mix: Current Trends and Future Needs, UK Government Office for Science.

Confederation of British Industry \& Pearson (2019), Education and Learning for the Modern World: CBI/Pearson Education and Skills Survey, CBI, London.

Daubney, K. (2020), "Extracted employability: the employability value of what is taught", in Norton, S. and Dalrymple, R. (Eds), Enhancing Graduate Employability: A Case Study Compendium, Advance HE, York, pp. 89-93.

DeKeyser, R. (2015), "Skill acquisition theory", in VanPatten, B. and Williams, J. (Eds), Theories in Second Language Acquisition: An Introduction, 2nd ed, Routledge, NY and London, pp. 94-112.

Department for Education (2011), Teachers' Standards (Overview), available at: https://assets. publishing.service.gov.uk/government/uploads/system/uploads/attachment_data/file/665522/ Teachers_standard_information.pdf (accessed 26 August 2020).

Department for Education (2013), History Programmes of Study: National Curriculum for England, available at: https://www.gov.uk/government/publications/national-curriculum-in-englandhistory-programmes-of-study/national-curriculum-in-england-history-programmes-of-study (accessed 26 August 2020).

Department for Education (2014a), GCE AS and A Level Subject Content for Computer Science, available at: https://assets.publishing.service.gov.uk/government/uploads/system/uploads/ attachment_data/file/302105/A_level_computer_science_subject_content.pdf (accessed 26 August 2020).

Department for Education (2014c), Geography: GCE AS and A Level Subject Content, available at: https://assets.publishing.service.gov.uk/government/uploads/system/uploads/attachment_data/ file/388857/GCE_AS_and_A_level_subject_content_for_geography.pdf (accessed 26 August 2020).

Department for Education (2014d), GCE AS and A Level Subject Content for History, available at: https://assets.publishing.service.gov.uk/government/uploads/system/uploads/attachment_data/ file/302102/A_level_history_subject_content.pdf (accessed 26 August 2020).

Department for Education (2014e), Mathematics Programmes of Study: Key Stage 4, available at: https://assets.publishing.service.gov.uk/government/uploads/system/uploads/attachment_data/ file/331882/KS4_maths_PoS_FINAL_170714.pdf (accessed 26 August 2020).

Department for Education (2015a), Philosophy: GCE AS and A Level Subject Content, available at: https://assets.publishing.service.gov.uk/government/uploads/system/uploads/attachment_data/ file/593841/Philosophy_AS_and_A_level_formatted.pdf (accessed 26 August 2020).

Department for Education (2015b), Science Programmes of Study: National Curriculum for England, available at: https://www.gov.uk/government/publications/national-curriculum-in-englandscience-programmes-of-study/national-curriculum-in-england-science-programmes-of-study (accessed 26 August 2020). 
Department for Education (2018), Careers Guidance and Access for Education and Training Providers: Statutory Guidance for Governing Bodies, School Leaders and School Staff, available at: https:// assets.publishing.service.gov.uk/government/uploads/system/uploads/attachment_data/file/ 748474/181008_schools_statutory_guidance_final.pdf (accessed 26 August 2020).

Department for Education (2019), Participation in Education, Training and Employment by 16-18 Year Olds in England: End 2019, available at: https:/assets.publishing.service.gov.uk/government/ uploads/system/uploads/attachment_data/file/893657/16-18_participation_and_NEET_ statistics_main_text.pdf (accessed 10 October 2020).

Gatsby Foundation (2014), Good Career Guidance, available at: https://www.gatsby.org.uk/uploads/ education/reports/pdf/gatsby-sir-john-holman-good-career-guidance-2014.pdf (accessed 10 May 2015).

Harvey, L. (2003), On Employability, Higher Education Academy, York.

Hillage, J. and Pollard, E. (1998), Employability: Developing a Framework for Policy Analysis, Department for Education and Employment, London.

Hudson, B., Henderson, S. and Hudson, A. (2015), "Developing mathematical thinking in the primary classroom: liberating students and teachers as learners of mathematics”, Journal of Curriculum Studies, Vol. 47 No. 3, pp. 374-398.

Institute of Student Employers (2014), The ISE Annual Survey, Institute of Student Employers, London.

Institute of Student Employers (2017), The ISE Annual Survey, Institute of Student Employers, London.

Institute of Student Employers (2019), The ISE Annual Survey, Institute of Student Employers, London.

Institute of Student Employers (2020), The ISE 2020 Development Survey: Trends, Benchmarks and Insights, Institute of Student Employers, London.

Knight, P.T. and Yorke, M. (2003), "Employability and good learning in higher education”, Teaching in Higher Education, Vol. 8 No. 1, pp. 3-16.

Organisation for Economic Co-operation and Development (2019), OECD Skills Strategy 2019: Skills to Shape a Better Future, OECD Publishing, Paris, doi: 10.1787/9789264313835-en.

Quality Assurance Agency, Subject Benchmark Statements, available at: https:/www.qaa.ac.uk/ quality-code/subject-benchmark-statements (English, 2015; Dietetics, 2017, accessed 26 August 2020).

Thijssen, J.G.L., Van der Heijden, B.I.J.M. and Rocco, T.S. (2008), “Toward the employability-link model: current employment transition to future employment perspectives”, Human Resource Development Review, Vol. 7 No. 2, pp. 165-183.

Yates, J. (2013), The Career Coaching Handbook, Routledge, London.

Yorke, M. (2004), Employability in Higher Education: What it Is - what it Is Not, Generic Centre, Learning and Teaching Support Network, York, Later edition (2006), Higher Education Academy/ESECT, York.

\section{Further reading}

Blackmore, P., Bulaitis, Z.H., Jackman, A.H. and Tan, E. (2016), Employability in Higher Education: A Review of Practice and Strategies Around the World, Pearson, London.

Brown, J., Gosling, T., Sethi, B., Sheppard, B., Stubbings, C., Sviokla, J., Williams, J., Zarubina, D. and Fisher, L. (2018), Workforce of the Future: The Competing Forces Shaping 2030, PwC, available at PwC website: https://www.pwc.com/gx/en/services/people-organisation/workforce-of-thefuture/workforce-of-the-future-the-competing-forces-shaping-2030-pwc.pdf (accessed 26 August 2020).
Employability value of school curricula

\section{.}


JWAM

13,1

116
Carnell, B. and Fung, D. (2017), Developing the Higher Education Curriculum: Research-Based Education in Practice, UCL Press, London.

Department for Education (2014b), GCE AS and A Level Subject Content for English Literature, available at: https://assets.publishing.service.gov.uk/government/uploads/system/uploads/ attachment_data/file/302110/A_level_English_literature_content.pdf (accessed 26 August 2020).

Department for Education (2015c), Physical Education: AS and A Level Content, available at: https:// assets.publishing.service.gov.uk/government/uploads/system/uploads/attachment_data/file/ 397578/GCE_AS_and_A_level_subject_content_for_PE.pdf (accessed 26 August 2020).

Department for Education (2017), Ancient Languages: AS and A Level Content, available at: https:// assets.publishing.service.gov.uk/government/uploads/system/uploads/attachment_data/file/ 595965/ALevel-Ancient_languages.pdf (accessed 26 August 2020).

Jones, C. and Penaluna, A. (2013), "Moving beyond the business plan in enterprise education", Education and Training, Vol. 55 Nos 8/9, pp. 804-814.

PSHE Association (2017), PSHE Education Programme of Study: Key Stages 1-5, available at: https:// www.pshe-association.org.uk/system/files/PSHE $\% 20$ Education $\% 20$ Programme $\% 20$ of $\%$ 20Study \%20\%28Key \%20stage\%201-5\%29\%20Jan\%202017_2.pdf (accessed 26 August 2020).

Williams, S., Dodd, L.J., Steele, C. and Randall, R. (2016), "A systematic review of current understandings of employability", Journal of Education and Work, Vol. 29 No. 8, pp. 877-901.

\section{Corresponding author}

Kate Daubney can be contacted at: kate.daubney@careers.lon.ac.uk

For instructions on how to order reprints of this article, please visit our website:

www.emeraldgrouppublishing.com/licensing/reprints.htm

Or contact us for further details: permissions@emeraldinsight.com 